\title{
Motives For Purchasing Artwork, Collectibles And Antiques
}

Mohammad Ali Zolfagharian, University of Texas-Pan American, USA Angelica Cortes, The University of Texas-Pan American, USA

\begin{abstract}
Art is disaggregated into tangible and intangible offerings. Intangible art is one-time experiences of aesthetical and nostalgic products with no post-consumption exchange value. Tangible art preserves post-consumption exchange value. While psychographics of the consumers of intangible art are well-established, consumers of tangible art are under-researched. This research identifies and measures 16 different motives that underlie the purchase of artwork, collectibles and antiques. Heavy-consumers are found to score significantly higher than light-consumers on 8 of these motives: expected price fairness (economic); social acceptability and group identification (normative); aesthetics, pleasure and immersion (hedonic); culture (intellectual); and harmony. Findings are discussed and implications and limitations are also included.
\end{abstract}

\section{INTRODUCTION}

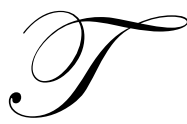

he generality of findings in consumer behavior literature, for a considerable part, suffers from tenacity in the selection of study objects (Hirschman \& Holbrook 1982) and singularity in perspective. For example, economic/utilitarian perspective has focused on acquisition decisions using packaged foods and durable goods as study objects whereas experiential/hedonic approach has researched consumption behavior using performing and plastic arts (Hirschman \& Holbrook 1982). Utilitarian view has studied brand choice whereas experiential view has looked at product use. There is ample need to bridge these gulfs by plurality in perspective and cross-product-class investigations. One area for such consumer behavior research is arts; an area that has received blinkered attention across its heterogeneous branches.

The tradition of "studying artwork to understand consumption" (Holbrook \& Grayson 1986, p. 380) has, by and large, focused on the consumers of theatrical performance and heritage/fine-art museums. Marketing academe has witnessed much conceptual analysis (e.g., Caldwell 2002, Goulding 2000, and Holbrook \& Grayson 1986) and numerous profiling studies (e.g., Todd \& Lawson 2001, Hanna \& Wagle 1989, and Nielsen \& McQueen 1974) on the consumers of art services. Interestingly, almost no study has provided a psychographic account of the buyers of the actual (versus one-time visits of) Artwork, Collectibles, and Antiques (ACA). Even theoretical work on ACA is still infantile despite Nielsen \& McQueen's (1974, p. 609) early warning that "there is no arts consumer behavior theoretical tradition."

Buyers of artwork can be divided into two categories: institutional and individual. Institutional buyers of artwork are often, primarily concerned with economic benefits of their investment. This is not necessarily the case for a majority of individual buyers, who might be driven by other (e.g., normative and hedonic by Celsi et al. 1993) motives in addition to economic ones. Researchers are yet to underscore the nature of the motivations undergirding the acquisition of these tangible, symbol-laden products. Two interesting questions are: "Can non-economic motives, e.g., hedonism, explain the behavior of ACA buyers?" and "How important are such motives in comparison to economic motives?"

The purpose of this article is twofold: (1) to explore the motivations underlying consumer acquisition of ACA and (2) to give further voice to the attempts (e.g., Babin et al. 1994) that promote plurality in research perspective by allowing both economic and non-economic views rival over the explanation of consumer behavior. The focus is on individual, not institutional, buyers. Related streams of research such as studies of motivation, 
ethnographic studies of the consumption of arts and of risky sports, and economic studies of investments in arts will help develop the main theoretical framework.

We proceed with a brief discussion of the literatures of motivation, art offerings, and risky-sports. Then, a conceptual model (see Figure 1) will elaborate the various motives of the consumers of ACA. Finally, a research survey undertaken to validate the substantive hypotheses will lead us to the discussion and implications of the findings and directions for future research.

\section{Figure 1: The Conceptual Model}

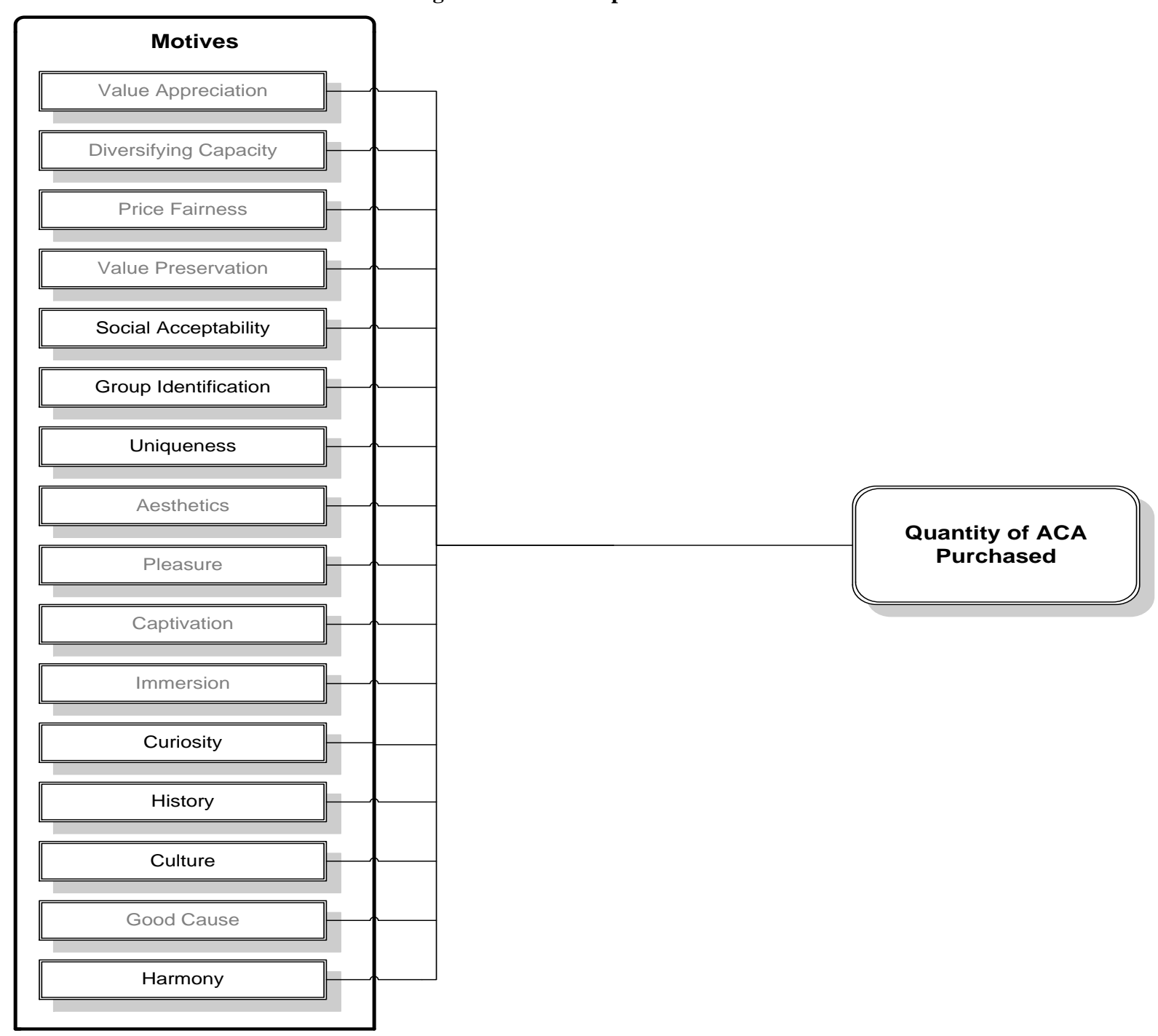

\section{LITERATURE REVIEW}

McClelland (1987, p.590) defines motivation as "a recurrent concern for a goal state based on a natural incentive; a concern that energizes, orients, and selects behavior". His comprehensive research on motivation (McClelland 1953, 1955, and 1961) has identified four classes of motives: needs for achievement, affiliation, power, and uniqueness/novelty. This taxonomy, while broadly explaining people's behavior, is not sufficiently specific to tease out the needs and wants that exclusively motivate the purchase and consumption of ACA. The more concrete 
and domain-specific findings of ethnographic and empirical studies in the areas of arts and risky sports might be more relevant. An exception is McClelland's need for uniqueness/novelty, which constitutes a distinct class of motives in this research.

\section{Art Offerings}

Synesthesia of aesthetics and nostalgia are the two major sources of value underlying the marketing of ACA (Schindler \& Holbrook 2003 and Joy \& Sherry 2003). Firms either market one-time experiences of those sources (e.g., museums) or sell products that contain such values (e.g., galleries and auctions). The former is a service (intangible), which leaves only, or at least primarily, a memorable hedonic (multisensory, fantasy, or emotive) value in consumer mind (Hirschman \& Holbrook 1982). The latter is a product (tangible), which inventories different types of values (e.g., sensation and economic). It has been suggested that sensation-seeking (hedonism) and communal norms explain why consumers frequent museums and theatres (e.g., Joy \& Sherry 2003, Caldwell 2002, and Belk 1999 in museums literature) as well as risky-sports (e.g., Arnould \& Price 1993, Celsi et al 1993, Shoham et al. 1998, and Hopkinson \& Pujari 1999). However, motivation behind purchasing tangible ACA, unlike that of its service version, is blurred. On the one hand, investment literature has compared them with diamond, gold, real estate, and financial securities in terms of economic return in the short- and long-term (e.g., Angello 2002, Rengers \& Velthuis 2002, Ekelund et al. 2000, Flores et al. 1999, Bates 1983). On the other hand, historically, many individual buyers, including collectors, have rarely sold their ACA (Bates 1983 p. 241) even in the face of exceptionally bull selling markets. It is not clear whether Bell's (1992) idea that the major property of a product is its manufactured form rather than consumer's feeling holds here. There is a need to identify the nature and significance of various motives underlying the acquisition of ACA.

\section{Risky-Sport Literature}

Research on risky sports (e.g., Arnould \& Price 1993) can offer valuable insights. Beside the differences, there might be sufficient overlap between various feelings sought, and reasons cited, by the consumers of arts and consumers of risky sports. Several major similarities, four of which are cited below, exist between the two groups of consumers. First, consumers of ACA, like risky-sport participants, seek certain intangible affective experiences (Joy $\&$ Sherry 2003). Second, Hopkinson and Pujari (1999) suggest that participation in risky sports is a sort of hedonic consumption and that ACA consumption shares several hedonic characteristics with risky-sport consumption. Third, like risky-sport participants, consumers of ACA are non-materialists who value experience above possession (see Richins 1994b). Finally, in both risky sports and ACA contexts, consumers (a) play a significant role in the production of product meanings and (b) are produced through consumption, which is an act of identification. In other words, consumers are highly involved in the production and consumption of meanings in both contexts.

Celsi et al. (1993) and Arnould \& Price (1993) provide similar ethnographic accounts of the motives and experiences of risky-sport consumption. The former classify the motives into normative (compliance, group identity, and communitas), efficacy (survival, achievement, personal identity), and hedonic (thrill, pleasure, and flow). The latter suggest three main categories of motives: communitas, personal growth and renewal, and harmony with nature. Hopkinson \& Pujari (1999) discuss in detail the similarities and differences between these two typologies. A comparison between these ethnographic studies and research in arts consumption (e.g., Joy \& Sherry 2003 and Hirschman \& Holbrook 1982) results in the identification of the following observations:

1. For 'thrill', 'pleasure', and 'flow' experiences (Celsi et al. 1993) derived from risky sports, there are 'multisensory stimulation', 'emotive arousal', and 'immersion' (Hirschman \& Holbrook 1982) embedded in ACA.

2. For 'harmony with nature' and 'personal growth and renewal' (Arnould \& Price 1993) found in risky sports, there are 'aesthetic-seeking' (Joy \& Sherry 2003) and 'historic and fantasy imagery' (Hirschman \& Holbrook 1982) potencies in ACA.

3. Compliance and group identity cited by Celsi et al. (1993) also motivate consumers of ACA. The term 'social acceptability' rather than compliance sounds more appropriate for our purpose. Based on these similarities, we consider and operationally define a variety of economic and non-economic motives in order to build a theoretical framework of the motivations of ACA buyers. 


\section{Economic Motives}

Research of the 60's and 70's (e.g., Rush 1961, Keen 1971, and Stein 1973) maintain that ACA buyers are motivated by economic considerations such as expected value appreciation, and portfolio diversification (Bates 1983). Pioneering advocates of this view focused on designing mathematical valuation models/indices and argued that oil paintings were no more or less attractive than stocks (Stein 1973). However, we posit that (1) a majority of ACA buyers do not have high economic expectations such as price appreciation and diversifying capacity and (2) two other considerations: perceived price fairness and expected value preservation (as contrasted with value depreciation) explain their economic concerns more precisely.

Hypothesis 1: ACA buyers' scores on expected value appreciation and diversifying capacity are significantly lower than their scores on both of expected value preservation and price fairness.

Hypothesis 2: Heavy-buyers score significantly higher than light-buyers on expected (a) value preservation and (b) price fairness.

\section{Normative Motives}

Ethnographic studies have revealed the importance of normative or communal motives among risky-sport subcultures. What motivates new consumers of a risky sport at the first trial is the need/pressure for 'compliance' with others' expectations Celsi et al. 1993). Group polarization produces increased risk acceptance in group decision contexts (Wallack et al. 1962 and Winter 1973). Celsi et al. (1993) explain that, with repeat trials, pressure for compliance wanes and 'identification' with new subculture emerges ....and increased technical skills result in enhanced social status.

Similar to the normative facet of risky sports are social and sub-cultural pressures for crystallized appreciation and understanding of aesthetics and nostalgia. ACA consumers are often motivated by their need for social acceptability and group identification, especially if their network members have explicit or implicit norms regarding arts. Social acceptability is one's degree of compliance with the environment (Celsi et al. 1993). It is a concern in an individual regarding whether and to what extent others in the society approve of her qualities implicitly or explicitly (Bhattacharaya 1995). Group identification is one's desire to be thought of as affiliated with a certain cultural or non-cultural idea, cause, and/or group of people. Perhaps, the most convenient crystallization of art appreciation is to collect ACA.

Hypothesis 3: Heavy-buyers score significantly higher than light-buyers on (a) social acceptability and (b) group identification motives.

\section{Uniqueness Motive}

Consumers driven by need for uniqueness seek opportunities to create actual or symbolic differences between themselves and the rest of the world. Belk (1988) shows how one's belongings represent a majority of her unique identity. ACA, as tangible products, are probably ideal belongings as far as expression of uniqueness is concerned. ACA derive their values mainly from being representative of aesthetic novelty, nostalgic uncommonness and, in a more general sense, expressive rarity. Thus, possessing them is probably an effective means of differentiating oneself from social commonalities. Need for uniqueness, as defined by Snyder \& Fromkin (1980) is roughly parallel to Celsi et al.'s (1993) self-identity motive, which is distinct from group identification. With the latter, the consumer acquires ACA to differentiate herself from the public and to relate herself to a certain group of people (a subculture). In the former, the consumer differentiates herself not only from the public but also from the members of any subculture. Only when social and cultural ties are strong enough, consumers become increasingly concerned with their new self-identity. This stage is more attainable for creators, experts, collectors, and heavy users of ACA, who often attempt to establish self-identity and attain unique, personal images through involvement in arts. Occasional buyers of ACA are less likely to engage in such purposive efforts. They might seek satisfaction from their uniqueness need in ways other than art consumption. But which of the two groups of consumers have comparatively higher levels of uniqueness motive; the heavy or the occasional consumers of ACA? 
Hypothesis 4: Heavy-buyers score significantly higher than light-buyers on uniqueness motive.

\section{Hedonic Motives}

Hedonism is a by-nature quality in all, though differentially across, consumers. Marketing does not create hedonic needs and wants; it only surfaces them (O'Shaughnessy \& O'Shaughnessy 2002). Consumers, in their acquisition and consumption activities, semiconsciously seek multisensory stimulations (tastes, sounds, scents, tactile impressions, and visual images), historic and fantasy imagery, and emotive arousal (e.g., joy, jealousy, fear, rage, and rapture) (Hirschman \& Holbrook 1982, Freud 1955). Consumption, in this sense, is a means by which people imaginatively construct reality (Singer 1966) over and over again. Preference for hedonic alternatives is stronger when they are uncertain, described as prizes (O'Curry \& Strahilevitz 2001), or offered as promotional services at no extra or separate charge (Wakefield \& Barnes 1996).

Salient dimensions of hedonic consumption vary across studies. In shopping literature, Babin et al. (1994) suggest enjoyment, excitement, captivation, escapism, and spontaneity. In risky-sport literature, Hopkinson \& Pujari (1999) propose enjoyment, self-expression, communitas, addiction, danger, and competition while Celsi et al. (1993) suffice to thrill, pleasure, and flow. Finally, in arts literature, Joy \& Sherry (2003) have implied aesthetics, immersion, and fantasizing. These dimensions activate behaviors like variety seeking and impulse purchase (Mowen \& Minor 2000 and Wakefield \& Barnes 1996). The results of our 2 focus groups sessions helped identify the most relevant and parsimonious set of dimensions. This set contains aesthetics, pleasure, captivation, and immersion. Aesthetics relates to the comprehension of the nicety and beauty of the lines, shapes, colors, and meanings found in ACA. Pleasure is the joy, the fun that the individual experiences during her synesthesia of aesthetics. Captivation is a quality in ACA that attracts and captures one's attention and sensory capacity for reasons other than aesthetics. Immersion is a state defined by maximal sensory and imaginative grip of the ACA. This is, perhaps, comparable to Csikszentmihalyi's (1974) flow experience. The main difference is in the requisite of the experience. Immersion might occur with an inborn talent or passion and without any acquired skills. This is not true of flow.

Hypothesis 5: Heavy-buyers score significantly higher than light-buyers on (a) aesthetics, (b) pleasure, (c) captivation, and (d) immersion motives.

\section{Intellectual Motives}

Knowing that cultural patrons are the best market for performing arts (Andreasen \& Belk 1985), one expects this finding to be applicable to ACA, which are obviously representative of certain cultures and subcultures. ACA can be valuable when they (1) contain information or symbols of cultures, (2) are traceable to specific historical characters, events, and facts, or (3) have been created sufficiently in the past to be considered historical items. Intellectual interest in certain cultures, subcultures, or histories sometimes strongly motivates acquisition and consumption of ACA. This interest is distinct from group-identification motive for two reasons. First, consumers' interest in particular cultures or subcultures might exist long before they are motivated to identify with specific groups (Veroff 1982). Second, even after consumers have recognized specific cultures or subcultures and desire to be associated with them, the need for cultural and historical information still remains. Normative motives do not encompass and explain this type of need.

We also posit that consumers sometimes acquire artwork to satisfy their intellectual curiosity. This curiosity is a rather abstract feeling. It might be thought of as an intellectual unease with or attachment to an artwork resulting in an acquisition decision. Zeigarnik effect explains a facet of intellectual curiosity (MacLachlan 1983).

Hypothesis 6: Heavy-buyers score significantly higher than light-buyers on (a) curiosity, (b) history, and (c) culture motives.

\section{Good Cause Motive}

There were frequent implications in our focus group that buying artwork means contributing to a good cause. Intuition suggests that an effective way of supporting a certain artist or a specific sort of art is purchasing 
relevant artwork. Participants in the focus group sessions further revealed that consumers do not equate contribution to a good cause (purchasing specific artwork) with donation. In the former, consumers engage in an economically justified exchange in which both sides perceive to have acquired an economically valued resource (artwork maintains economic value). In the latter, however, one side of the exchange gives economic resources and receives little or no economic resource in return. It is interesting that consumers try to purchase artwork at fair prices and, at the same time, feel they are contributing to a good cause. Focus group participants did not associate the purchase of collectibles and antiques with contribution to a good cause.

\section{Hypothesis 7: Heavy-buyers score significantly higher than light-buyers on good cause motive.}

\section{Harmony Motive}

Harmony, here, is both linked to and distinct from Arnould \& Price's (1993) 'harmony with nature,' which refers to 'communion' with nature (rivers: natural environment and scenery) and separation from 'civilization.' The link is in the difference that both river rafting and ACA consumption have from everyday utilitarian activities. ACA are symbolic objects laden with meanings and distinguished from a majority of other objects that surround us. Similarly, rivers are great natural scenery capable of awakening numerous affective states and distinguished from a majority of the scenes that encircle urban and suburban citizens. Therefore, both nature and ACA enable consumers to add flavor to their basic, utilitarian activities and to enjoy a more balanced life style. The difference is in the dissimilar sources of values that underlie the consumption of ACA versus river rafting. As cited before, synesthesia and nostalgia are the two main sources of the values of ACA. River rafting, however, is valuable primarily because it involves risk-taking and acquisition of certain skills.

Hypothesis 8: Heavy-buyers score significantly higher than light-buyers on harmony motive.

\section{METHOD \& ANALYSIS}

For the purpose of this study, artwork includes transportable oil and non-oil paintings (on canvas, wood, stucco, plastic, etc.), exquisite tapestries, and framed carpets. Collectibles include furniture, stamps, coins, bottled wine, firearm, jewelry, and musical instruments that are 15 to 99 years old. Antiques comprise all these items provided they are at least a century old (Crispell 1988). To qualify for this survey, the ACA should have a price range of $\$ 50-\$ 15,000$.

The instrument (a multi-item, mutli-construct questionnaire) for this research is partially borrowed and adapted and partially developed. The 8 items measuring self-identity are borrowed and adapted from the 'creative choice' section of the 'Need-for-Uniqueness' scale developed by Tepper-Tian et al. (2001). These items are deemed appropriate because the definitions of need for uniqueness and self-identity are sufficiently similar, if not identical. Tepper-Tian et al. (2001) report reliability measures of 0.81 and 0.73 for one- and two-year separated retests, respectively. The Creative Choice sub-scale includes 11 items, 3 of which deemed inappropriate because of weak main loading during our pilot studies. To be parsimonious, the sub-scale rather than the entire scale was used since the first and second pilot studies showed correlations of 0.95 and 0.97 between the subscale and the whole scale. The authors developed the remaining of the items in the following manner. Initially, we used some of the adjectives in Caldwell's (2001) review of motivations and Babin et al.'s (1994) hedonic scale and developed a few items (see Table 1). Secondly, a battery of original items were developed and subsequently improved during our 2 focus group sessions. Participants of these sessions were college students and their relatives and friends. The use of 22 reversecoded items and randomizing the sequence of items within each class of motives are supposed to have reduced systematic error of the instrument. Six categorical items captured respondents' gender, age, religion, ethnicity, education, and (perceived) social class. The items measuring the motives were on a 5-point Likert scale, anchored between "strongly agree" (5) and strongly disagree (1). Past purchase behavior was measured by asking the respondents to write how many ACA they had purchased in the last 4 years. Finally, two convenience samples of 187 and 212 undergraduate students responded to all of the borrowed and the self-developed items. The samples were temporally ( 25 days) separated. They served as independent pilot studies that helped refine the wording and purify the composition of the scale items. 


\section{Data Collection}

Respondents are of two classes: (1) customers of a chain art-store who, according to the store's data base, have purchased 5 or more ACA in the last 4 years, and (2) a convenience sample of non-student, professional adults. These samples were located in the metropolitan cities in Southeastern and Southwestern parts of the U.S, respectively. Participants specified how many ACA they had bought in the last 4 years under each of the 9 categories as follows. Each of artwork, collectibles and antiques constituted one category under which three price levels (low-price $\$ 50-\$ 500$, medium-price $\$ 501-\$ 1,500$ and high-price $\$ 1,501-\$ 15,000$ ) further categorized particular ACA. The price categories emerged within the focus group sessions and were calibrated in the pilot studies, and later with the expert opinions provided by the chain art-store. The usable questionnaires amounted to 306 and 338 creating response rates of $44 \%$ and $97 \%$ for the first and second samples, respectively.

\section{Analysis}

The final usable questionnaires included more female (384) than male (257) respondents. The only demographic difference between the two samples was education: The average education level was 'bachelor's degree' for the chain art-store sample, and 'some college' for the other sample. In both samples, females outnumbered males; over $60 \%$ of respondents were between 36 and 55 years of age; and social class distribution was rather normal with an average of middle class. A cross-tab test between early and late respondents suggests that non-response bias is not unduly influencing the data. The number and value of ACA purchased in the last 4 years was used in a cluster analysis. Two significantly distinct clusters were identified and termed 'Heavy-buyers' and 'light-buyers'.

For each of the 5 classes of motive, a Varimax-rotated common factor analysis was performed to examine itemized loadings and emerging factors, which turned out as highly consistent with the theorized dimensions. A total of 3 items were dropped due to inconsistent loadings. Table 1 presents the items, loadings, and the observed factors.

Measures of internal reliability, Cronbach alphas, ranged from 0.66 to 0.82 and were mostly around 0.70 across dimensions of motives (see Table 2). Thus, alphas promise adequate level of internal reliabilities. The factor items were next averaged and the composite scores were used to build statistical models of the conceptualized relations. The mean scores across the last two dimensions of economic motives (perceived price fairness and expected value preservation) and all dimensions of normative, uniqueness, hedonic, intellectual, good cause, and harmony motives ranged between 3.1 and 3.6 on a 5-point Likert scale. As a conclusion, all of our conceptualized motives do exist in typical consumers.

Under each class of motives, the within-dimension reliabilities evidenced by Cronbach alphas are sufficiently high and significantly stronger than the between-dimension correlations. Thus, convergent and discriminant validities of the hypothesized dimensions under each class of motives are supported (Churchill 1979). The between-dimension correlations range from -0.30 to 0.36 . This implies fair divergence between theorized dimensions and lack of any collapsible pairs. The item-by-item correlation matrix (not shown here) supported the above observations.

The economic motives suggested by investment literature (value appreciation and diversifying capacity) and our proposed economic motives (value preservation and price fairness) are negatively correlated, showing the likely (but not warranted) substitutability of these two pairs of motives. Furthermore, the mean score of the former pair (value appreciation $=2.80$ and diversifying capacity $=2.21$ ) were significantly lower than those of the latter pair (price fairness $=3.53$ and value preservation $=3.65$ ). The two pairs showed similar standard deviation. These facts are in favor of hypothesis 1 . Although our economic motives enjoy more salience, we shall include the former economic motives in the subsequent analyses to observe their further behavior. 
Table 1: Dimensions and Scale Items of Motives, Rotated Principal Component, and Other Statistics

\begin{tabular}{|c|c|c|c|c|c|}
\hline \multicolumn{2}{|r|}{ Economic Motives (item 15 deleted for weak mainloading of 0.41, which pulled the alpha down to 0.620) } & \multirow{2}{*}{$\frac{1}{0.684}$} & \multirow[t]{2}{*}{2} & \multirow[t]{2}{*}{3} & \multirow[t]{2}{*}{4} \\
\hline Value & 1 Buying collectibles is a financial investment & & & & \\
\hline \multirow[t]{4}{*}{ Appreciation } & 2 The good thing about a collectible is its price-increase over time & 0.756 & & & 0.244 \\
\hline & 3 I expect to sell a collectible for a price greater tha what I pay for it & 0.685 & & 0.323 & \\
\hline & 4 The reason I might buy a collectible is to make money & 0.615 & & 0.302 & \\
\hline & 5 Investment in real estate and investment in collectibles are closely comparable & 0.668 & & & \\
\hline Diversifying & 1 If I buy a collectible, I am responding to the saying: 'Don't keep all your eggs in one basket' & & 0.601 & & \\
\hline \multirow[t]{4}{*}{ Capacity } & 2 I try to diversify my investment by considering collectibles, stock options, etc & & 0.634 & & \\
\hline & 3 To reduce my total investment risk, I might consider buying collectibles & & 0.671 & 0.226 & \\
\hline & 4 I never compare collectibles with investment opportunities & & 0.531 & & \\
\hline & 5 A good alternative to investing in bonds and stocks is buying collectibles & & 0.714 & & \\
\hline Price & 1 Like other products, collectibles should sell at a fair price & & & 0.662 & \\
\hline \multirow[t]{3}{*}{ Fairness } & 2 I wouldn't buy a collectible for an unfair price even if I really liked it & & & 0.713 & \\
\hline & 3 Buying expensive collectibles is justified but buying unreasonably-priced collectibles is a mistake & & & 0.742 & \\
\hline & 4 Price is not an issue when it comes to collectibles & & & 0.708 & \\
\hline Value & 1 One of the things that encourage me to buy collectibles is their price preservation & & & & 0.704 \\
\hline \multirow[t]{2}{*}{ Preservation } & 2 A collectible that remains at the same price and doesn't become more expensive over time is not & buy & & & 0.778 \\
\hline & 3 I don't care if my collectibles don't become more expensive over time; they should retain their cas & though & & & 0.766 \\
\hline \multicolumn{3}{|c|}{ Normative Motives (item 18 deleted for weak main loading of 0.47, which pulled the alpha down to 0.73 ) } & 1 & 2 & 3 \\
\hline Social & 1 Collectibles help me impress others & & 0.680 & & \\
\hline \multirow[t]{6}{*}{ Acceptability } & 2 Collectibles make me more socially desirable & & 0.672 & & \\
\hline & 3 Collectibles can help me start and hold interesting conversations with others & & 0.696 & & \\
\hline & 4 Collectibles have nothing to do with how socially acceptable I am & & 0.676 & & \\
\hline & 5 Collectibles make me more sociable & & 0.737 & & \\
\hline & 6 At times when I find no subject to talk about, collectibles fill the blank successfully & & 0.649 & & \\
\hline & 7 Collectibles enhance my social image & & 0.636 & & \\
\hline Group & 1 like collectibles because they can link me to my family and friends & & & & 0.760 \\
\hline \multirow[t]{4}{*}{ Identification } & 2 Collectibles do not strengthen my relationship with my friends & & & & 0.750 \\
\hline & 3 I feel I am closer to my friends when I share the same art interests with them & & 0.252 & & 0.519 \\
\hline & 4 I have improved my relationship with friends by developing common art interests & & & & 0.747 \\
\hline & 5 To make friends with a certain group of people, I might involve myself in collectibles that they like & & & & 0.612 \\
\hline
\end{tabular}


Table 1 continued

Self ldentity 1 Having an unusual collectible is a way of telling others how different I am 0.56

(Tepper- 2 Unusual collectibles help me create a more distinctive personal image

et al. 2001) 3 One-of-a-kind collectibles contribute to the style that is all my own

4 Buying a collectible is like looking for something that can communicate one's uniqueness

5 Collectibles bring a personal image that can't be duplicated

6 Having an eye for collectibles that are interesting and unusual assist me in establishing a distinctive image

0.670

7 Collectibles express one's individuality

\section{Hedonic Motives (item 10 deleted for two high cross loadings)}

Aesthetics $1 \mathrm{I}$ like collectibles because they are beautiful

2 Collectibles are among prettier things I can possess

0.71

3 I don't buy collectibles just because collectibles are beautiful objects

4 Collectibles can make my home or office look more beautiful

5 Collectibles are delicate and fascinating (C)

6 Collectibles can enhance the appearance of a place

Pleasure $\quad 1$ Collectibles are valuable because they are pleasing

2 Looking at the collectibles that I have makes me excited (C)

3 Collectibles are not more pleasurable than other products

4 Compared to other things I can buy, collectibles are more enjoyable

0.541

1 Every collectible has something that captures my attention

Captivation 1 Every collectible has some collectibles that I can't help staring at

3 I never pay for a collectible just because it is capable of catching my attention

4 Collectibles have a charm that captivates me for a few moments

Immersion 1 Looking at a collectible can help me totally forget about my problems (B)

2 Looking at collectibles can emotionally elate me

3 I can get myself totally lost in a collectible

4 One good thing about collectibles is that one feels engrossed by looking at them

0.703

0.714

0.682

0.656

0.775

5 Collectibles are not capable of escalating my emotions and feelings

6 I sometimes find myself immersed in my collectibles (B)

\section{Intelletual Motives (no item deleted)}

Curiosity $\quad 1$ I like collectibles because they make me curious

2 I might buy a collectible I don't quite understand so I can think about it at my convenience

0.298

3 I never buy a collectible just because it raises my curiosity

4 I sometimes buy collectibles just because they puzzle me

\begin{tabular}{ccc}
$\mathbf{1}$ & $\mathbf{2}$ & $\mathbf{3}$ \\
\hline & & 0.708 \\
0.240 & & 0.649 \\
& & 0.702 \\
& & 0.670 \\
\hline
\end{tabular}




\begin{tabular}{|c|c|c|c|c|}
\hline \multirow{5}{*}{ History } & & & & \\
\hline & 1 Collectibles contain history; hence, they are valuable & 0.695 & & \\
\hline & 2 If a collectible offers historical information, I might very well buy it & 0.713 & & \\
\hline & 3 I care for collectibles because they reflect the years gone by & 0.721 & 0.313 & \\
\hline & 4 Collectibles do not tell you anything about history, thus, they have no value & 0.708 & & \\
\hline \multirow[t]{5}{*}{ Culture } & 1 One thing that contributes to the value of collectibles is their being symbols of cultures & & 0.525 & \\
\hline & 2 I like to have collectibles that represent certain cultures or beliefs & & 0.641 & \\
\hline & 3 I don't buy a collectible just because it is a cultural product & & 0.631 & \\
\hline & 4 A collectible is valuable partially because it shows the culture its creator lives or lived in & & 0.657 & \\
\hline & 5 I like to buy things, including collectibles, that convey cultural meanings & & 0.678 & \\
\hline \multicolumn{2}{|c|}{ Other Motives (no item deleted) } & & 1 & 2 \\
\hline Good & 1 Whenever I buy a collectible, I feel I am contributing to a good cause & & 0.751 & \\
\hline \multirow[t]{3}{*}{ Cause } & 2 Those who never buy collectibles probably do not understand how important it is to help artists & & 0.766 & \\
\hline & 3 Buying collectibles doesn't do any good to the society & & 0.755 & 0.203 \\
\hline & 4 I can support art and artists by buying collectibles & & 0.756 & \\
\hline \multirow[t]{3}{*}{ Harmony } & 1 I buy collectibles for creating harmony in my life & & & 0.804 \\
\hline & 2 The collectibles that I buy add to the harmony of my home or work atmosphere & & & 0.715 \\
\hline & 3 Collectibles enable me to maintain balance between different aspects of $\mathrm{my}$ life & & & 0.807 \\
\hline
\end{tabular}

Notes: The anchor used was "strongly agree" (5) to "strongly disagree" (1).

'C' stands for Caldwell (2001) and 'B' for Babin et al. (1994). 
Table 2: Factor-by-Factor Correlation Matrix and Factor Statistics

\begin{tabular}{|c|c|c|c|c|c|c|c|c|c|c|c|c|c|c|c|c|c|c|}
\hline & & 1 & 2 & 3 & 4 & 5 & 6 & 7 & 8 & 9 & 10 & 11 & 12 & 13 & 14 & 15 & 16 & 17 \\
\hline \multirow[t]{4}{*}{ Economic } & 1. Value Appreciation & 1 & & & & & & & & & & & & & & & & \\
\hline & 2. Diversifying Capacity & 0.15 & 1 & & & & & & & & & & & & & & & \\
\hline & 3. Price Fairness & -0.09 & -0.13 & 1 & & & & & & & & & & & & & & \\
\hline & 4. Value Preservation & -0.09 & -0.30 & 0.19 & 1 & & & & & & & & & & & & & \\
\hline \multirow[t]{3}{*}{ Normat } & 5. Social Acceptability & 0.12 & 0.06 & -0.17 & -0.15 & 1 & & & & & & & & & & & & \\
\hline & 6. Group Identification & 0.13 & -0.03 & -0.13 & -0.11 & 0.44 & 1 & & & & & & & & & & & \\
\hline & 7. Uniqueness & -0.04 & -0.07 & 0.01 & 0.09 & 0.21 & 0.29 & 1 & & & & & & & & & & \\
\hline \multirow[t]{4}{*}{ Hedonic } & 8. Aesthetics & 0.05 & 0.08 & -0.06 & -0.08 & -0.03 & 0.16 & 0.07 & 1 & & & & & & & & & \\
\hline & 9. Pleasure & -0.01 & 0.06 & -0.03 & -0.04 & 0.32 & 0.26 & 0.10 & 0.49 & 1 & & & & & & & & \\
\hline & 10. Captivation & 0.04 & -0.09 & 0.07 & -0.08 & 0.16 & 0.27 & 0.18 & 0.22 & 0.36 & 1 & & & & & & & \\
\hline & 11. Immersion & 0.09 & 0.09 & 0.04 & -0.11 & 0.30 & 0.46 & 0.11 & 0.10 & 0.17 & 0.26 & 1 & & & & & & \\
\hline \multirow[t]{3}{*}{ Intellec } & 12. Curiosity & 0.15 & 0.15 & -0.15 & -0.13 & 0.24 & 0.12 & -0.02 & 0.06 & 0.11 & -0.08 & 0.21 & 1 & & & & & \\
\hline & 13. History & 0.07 & -0.09 & 0.03 & 0.06 & -0.06 & 0.12 & 0.02 & -0.08 & 0.01 & 0.14 & 0.17 & 0.23 & 1 & & & & \\
\hline & 14. Culture & 0.11 & -0.11 & -0.05 & 0.09 & -0.08 & 0.14 & 0.08 & -0.05 & -0.03 & -0.01 & -0.03 & 0.09 & 0.17 & 1 & & & \\
\hline \multirow[t]{3}{*}{ Othe } & 15. Good Cause & 0.02 & 0.12 & -0.16 & -0.10 & 0.53 & 0.36 & 0.21 & -0.01 & 0.20 & 0.16 & 0.38 & 0.34 & 0.07 & -0.10 & 1 & & \\
\hline & 16. Harmony & 0.13 & -0.12 & 0.08 & -0.03 & -0.03 & -0.01 & 0.01 & -0.01 & -0.05 & -0.01 & 0.03 & -0.08 & -0.09 & 0.05 & 0.29 & 1 & \\
\hline & 17. ACA & 0.04 & 0.05 & 0.12 & 0.08 & 0.18 & 0.11 & -0.08 & 0.10 & 0.12 & -0.01 & 0.10 & 0.07 & 0.04 & 0.09 & -0.05 & 0.10 & 1 \\
\hline \multicolumn{2}{|c|}{ Cronbach alpha } & 0.727 & 0.657 & 0.688 & 0.696 & 0.818 & 0.755 & 0.809 & 0.811 & 0.695 & 0.789 & 0.808 & 0.682 & 0.690 & 0.694 & 0.764 & 0.712 & \\
\hline \multicolumn{2}{|c|}{ Factor mean } & 2.795 & 2.214 & 3.534 & 3.649 & 3.166 & 3.182 & 3.395 & 3.282 & 3.289 & 3.409 & 3.263 & 3.136 & 3.268 & 3.407 & 3.094 & 3.401 & \\
\hline \multicolumn{2}{|c|}{ Factor standard deviation } & 0.797 & 0.709 & 0.768 & 0.825 & 0.774 & 0.738 & 0.677 & 0.842 & 0.781 & 0.807 & 0.832 & 0.746 & 0.743 & 0.659 & 0.870 & 0.882 & \\
\hline \multicolumn{2}{|c|}{$\%$ of variance by factor } & 0.191 & 0.164 & 0.152 & 0.114 & 0.301 & 0.254 & 0.211 & 0.232 & 0.194 & 0.148 & 0.107 & 0.249 & 0.217 & 0.184 & 0.334 & 0.266 & \\
\hline \multicolumn{2}{|c|}{ Total $\%$ of variance } & \multicolumn{4}{|c|}{0.621} & \multicolumn{3}{|c|}{0.766} & \multicolumn{4}{|c|}{0.681} & \multicolumn{3}{|c|}{0.650} & \multicolumn{2}{|c|}{0.600} & \\
\hline
\end{tabular}

Note: Correlations equal to or greater than 0.078 and 0.103 are significant at 0.05 and 0.01 , respectively. 
Table 3: Discriminant Analysis Results

\begin{tabular}{|c|c|c|c|c|c|c|c|c|c|}
\hline & & Wilk's Lambda & $\mathrm{F}$ & Sig & df1 & df2 & Cannonical Coeff & & \\
\hline \multirow[t]{4}{*}{ Economic } & 1. Value Appreciation & 1.04 & 1.34 & 0.22 & 1 & 639 & 0.02 & Box's M & 0.051 \\
\hline & 2. Diversifying Capacity & 0.97 & 1.45 & 0.23 & 1 & 639 & 0.11 & Eigenvalue & 0.075 \\
\hline & 3. Price Fairness & 0.99 & 4.03 & 0.04 & 1 & 639 & 0.19 & Cannonical Correlatior & 0.263 \\
\hline & 4. Value Preservation & 1.00 & 0.35 & 0.55 & 1 & 639 & 0.07 & Willk's Lambda & 0.931 \\
\hline \multirow[t]{3}{*}{ Normat } & 5. Social Acceptability & 0.98 & 10.23 & 0.00 & 1 & 639 & 0.42 & Chi Square & 45.337 \\
\hline & 6. Group Identification & 0.97 & 18.66 & 0.00 & 1 & 639 & 0.48 & Sig & 0.000 \\
\hline & 7. Uniqueness & 0.99 & 2.69 & 0.10 & 1 & 639 & -0.12 & & \\
\hline \multirow[t]{4}{*}{ Hedonic } & 8. Aesthetics & 0.98 & 19.93 & 0.00 & 1 & 639 & 0.49 & & \\
\hline & 9. Pleasure & 0.99 & 6.80 & 0.01 & 1 & 639 & 0.15 & & \\
\hline & 10. Captivation & 1.00 & 1.30 & 0.25 & 1 & 639 & -0.07 & & \\
\hline & 11. Immersion & 0.99 & 5.06 & 0.02 & 1 & 639 & 0.13 & & \\
\hline \multirow[t]{3}{*}{ Intellec } & 12. Curiosity & 1.06 & 1.63 & 0.20 & 1 & 639 & 0.03 & & \\
\hline & 13. History & 1.12 & 1.23 & 0.27 & 1 & 639 & 0.09 & & \\
\hline & 14. Culture & 1.01 & 4.25 & 0.05 & 1 & 639 & 0.12 & & \\
\hline \multirow[t]{2}{*}{ Othe } & 15. Good Cause & 0.99 & 1.08 & 0.30 & 1 & 639 & -0.05 & & \\
\hline & 16. Harmony & 0.99 & 6.68 & 0.02 & 1 & 639 & 0.15 & & \\
\hline
\end{tabular}

Notes: 1. Dependent variable was Total ACA Purchased with two categories: Heavy-buyers and light-buyers.

2. Independent variables were the different types of motives, measured using 5-point Likert scale. 
The two groups, light- and heavy-buyers, were then dummy-coded ( 0 and 1 , respectively) and the result was used as the dependent variable for a discriminant analysis. The 16 motivation dimensions served as the independent variables. Box's M-test of variance-comparability $(p=0.051)$ confirmed the applicability of the discriminant analysis for the comparisons between the two groups. The resulting eigenvalue of 0.075 , the canonical correlation of 0.263 , and the chi-square value of 45.38 suggest that the heavy- and light-buyers are significantly different in terms of motivation $(\mathrm{p}=0.000)$. Table 3 contains these statistics and per-dimension Wilk's Lambdas, $\mathrm{F}$ values, and canonical coefficients. As hypothesized, neither of the traditional economic motives (value appreciation and diversifying capacity) appeared significant. The results show that, of the remaining 14 motivation dimensions, 8 dimensions were significantly different across heavy- and light-buyers. The 8 dimensions include price fairness, social acceptability, group identification, aesthetics, pleasure, immersion, culture, and harmony. The direction of the canonical coefficients indicates that heavy-buyers score significantly higher than light-buyers on all of these 8 dimensions. These findings support hypotheses $2 \mathrm{~b}, 3 \mathrm{a}, 3 \mathrm{~b}, 5 \mathrm{a}, 5 \mathrm{~b}, 5 \mathrm{~d}, 6 \mathrm{c}$ and 8 . The findings fail to support hypotheses $2 \mathrm{a}, 4,5 \mathrm{c}, 6 \mathrm{a}, 6 \mathrm{~b}$, and 7 .

\section{DISCUSSION \& IMPLICATIONS}

Overall findings indicate that heavy- and light-buyers of ACA differ in terms of motivation. However, this role is not constant across all of the theorized dimensions/classes of motivation. Among the various classes of motives, normative and hedonic motives seem to be the most dominant since 5 of the 8 significant contributors to the motivational differences between heavy- and light-buyers of ACA belong to these two classes. Economic and intellectual motives are the second two dominant classes of motives, each containing only one significant dimension.

Social acceptability and group identification (normative) and aesthetics (hedonic) showed the highest Fvalues, the strongest associations with purchase quantity, and the most influential canonical coefficients. Thus, they can be thought of as the primary motivations that distinguish heavy-buyers from light-buyers. Pleasure (hedonic) and harmony are the next most salient motivations, followed by immersion (hedonic), culture (intellectual), and price fairness (economic). Finally, the motives value preservation (economic), uniqueness, captivation (hedonic), curiosity and history (intellectual), and good cause failed to significantly contribute to the motivational differences between heavy- and light-buyers.

The first pair of economic motives (expected value appreciation and diversifying capacity) suggested by investment literature (e.g., Angello 2002, Rengers \& Velthuis 2002, Ekelund et al. 2000, Flores et al. 1999, Bates 1983) are probably substitutable with the second pair of economic motives (expected value preservation and price fairness) for two reasons. First, the correlations between these two pairs of economic motives were negative, suggesting that typical consumers are driven either by the former or by the latter pair, but not by both pairs simultaneously (see Table 2). Second, the mean score of consumers on the first pair, on the average, is significantly lower than their scores on the second pair.

Value appreciation and value preservation are two mutually rival expectations that might motivate buyers of ACA. Buyers, who expect value appreciation, strive to sell their ACA for a higher price. On the other hand, buyers, who expect value preservation, simply require that their ACA sell at a price sufficiently close to the purchase price. Expected value appreciation is a profit-making mentality while expected value preservation is a mere loss-aversion mentality. Respondents' higher average scores on value preservation suggest that consumers of ACA are more concerned with value preservation than with value appreciation. Thus, value preservation might replace value appreciation.

Although this paper does not propose any rival motive to replace diversifying capacity, the findings cast doubt on its appropriateness for research on arts as far as individual consumers are concerned. Participants in our survey scored substantially lower (mean of 2.21) on this motive, compared with other economic motives. Diversifying capacity might be more relevant to institutional buyers than individual buyers of ACA. While suggesting further investigation on this motive, we propose a different economic motive: price fairness. Like value preservation, this motive enjoyed a high mean score. It was the only salient economic motive differentiating heavybuyers from light-buyers of ACA. Summing up the discussion of economic class, none of these motives, save for price fairness, is a salient differentiator between heavy- and light-buyers. First, price fairness was found to be a less 
important motive (using canonical coefficients) compared with other salient motives. Therefore, economic expectations are among the least important motives as far as art acquisition/consumption is concerned. Second, heavy-buyers' scoring significantly higher than light-buyers on this motive suggests that customers grow more price-conscious as they purchase more and more ACA.

The insignificance of uniqueness motive resembles a surprising finding, but it really is not. The literature (see Tepper-Tian et al. 2001) implies that buyers of ACA have higher need for uniqueness than do non-buyers. However, no previous research has examined how this need varies at different levels of ACA acquisition and consumption. More specifically, it isn't clear whether heavy-buyers are expected to have greater need for uniqueness than do light-buyers. Our findings suggest that the two groups do not differ in this respect. Perhaps, need for uniqueness, as a function of ACA purchase quantity is a non-linear relation.

\section{LIMITATIONS \& FUTURE RESEARCH}

Achieving valid measurement is difficult in behavioral research (Hirschman \& Holbrook 1982), especially when one uses self-report to tap into imagined aspects of acquisition and consumption. The first limitation of this article is reliance on consumers' reporting of their subconscious emotive and cognitive states and experiences that happened in the past. Readers should, thus, apply caution when interpreting the findings here. Experimental and longitudinal studies of ACA-buyers' motivations seem as a logical next step. Controlling for a greater number of interfering variables and/or tracking the salience of various motives over time can provide valuable insights.

The second limitation results from the heterogeneity across ethnic groups that make up the U.S. population. Unless they are replicated in several ethnic clusters, psychographic findings are not assertively generalizable to the entire society. Furthermore, it is interesting to investigate whether heavy-, light-, and non-buyers of ACA differ from one another on demographical bases such as gender, ethnicity, etc.

The third limitation relates to the temporal distance between respondents' actual behavior in the past and their current scores on motivation scales, which constituted the dependent and independent variables, respectively, in this study.

Future research should also consider replicating this study and further validate its findings. Although this research tried to consider a wide array of motives, there might be other sorts of motivation that potentially explain the psychographics or the behavioral intentions of ACA consumers. Therefore, future research should try to expand, re-categorize, and further elaborate on the list of motives.

The natures of the motives pleasure and harmony as functions of ACA-purchase quantity deserve further research. The findings here suggest that light-buyers are more strongly driven by pleasure and harmony than are heavy-buyers. Some interesting questions include: Do these motives follow an ' $S$ ' shape (logistic) function? Do they show negative slope at (very) large quantities of ACA purchase? Can binomial distribution and related procedures provide approximately reliable estimations and predictions of ACA-buyers' behavior?

Finally, we are yet to generate a better understanding of the relation between need for uniqueness and arts acquisition/consumption. Are they significantly correlated? If yes, how does the strength of uniqueness motive vary along different levels of art consumption?

\section{REFERENCES}

1. Andreasen, A.R. and R.W. Belk; "Predictors of attendance at the performing arts"; Journal of Consumer Research, Vol. 7, Sep 1980, 112-120

2. Angello, R.J.; "Investment return and risk for art: evidence from auctions of American paintings"; Eastern Economic Journal, 28, fall 2002, 4, 443-461

3. Arnould, E.J., and L.L. Price; "River magic: extraordinary experience and extended service encounter"; Journal of Consumer Research, Vol. 20, Jun 1993, 24-25 
4. Babin, B.J., W.R. Darden, and M. Griffin; "Work and/or fun: measuring hedonic and utilitarian shopping value"; Journal of Consumer Research, Vol. 20, 1994, 644-656

5. Bates, C.S.; "An unexplored international market - the art market"; Journal of the Academy of Marketing Science, Vol. 11, 3, summer 1983, 240-249

6. Belk, R. W.; "Materialism; trait aspects of living in the material world"; Journal of Consumer Research, Vol. 12, Dec 1985, 265-280

7. _ _ _ Belk, R.W. and Ronald Groves; "Marketing and Multiple Meanings of Australian Aboriginal Arts"; Journal of Macromarketing, June 1999, 19, 1, 20-33

8. _ _ _ _Possessions and the extended self"; Journal of Consumer Research, Vol. 15, Sep 1988, 139-168

9. Bell, C.; "How to invent service"; Journal of Services Marketing, Vol. 6, 1, winter 1992, 37-39

10. Bhattacharya, C.B., R. Hayagreeva, and M.A. Glynn; "Understanding the bond of identification: an investigation of its correlates among art museum members" Journal of Marketing, Vol. 59, Oct 1995, 46-57

11. Caldwell, M.; "Applying general living systems theory to learn consumers' sense making in attending performing arts"; Psychology \& Marketing, Vol. 18, 5, May 2001, 497-511

12. Caldwell, N.; "(Rethinking) the measurement of service quality in museums and galleries"; International Journal of Nonprofit and Voluntary Sector Marketing, Vol. 7, 2, 2002, 161-171

13. Celsi, R.L., R.L. Rose, and T.W. Leigh; “An exploration of high-risk leisure consumption through skydiving"; Journal of Consumer Research, Vol. 20, Jun 1993, 1-23

14. Churchill, Gilbert A.; "A paradigm for developing better measures of marketing constructs"; Journal of Marketing Research, 16, 1979, 64-73.

15. Crispell, D.; "Memories"; American Demographics, Nov 1988

16. Csikszentmihalyi, M.; "Flow: studies in enjoyment"; Public Health Service Grant, No. R01HM 22883-02, 1974

17. Ekelund, R., R. Ressler, and K. Watson; "The death-effect in art prices: a demand-side exploration"; Journal of Cultural Economics, Nov 2000, 283-300

18. Flores, R., V. Ginsburgh, P. Jeanfils; "Long- and short-term portfolio choices of paintings"; Journal of Cultural Economics, Aug. 1999, 193-210

19. Freud, S.; "Beyond the pleasure principle"; in the Standard Edition of the Complete Psychological Works of Sigmund Freud, 1955, Vol. 18, J. Strackey, ed., London: Hogarth Press

20. Goulding, C.; "The museum environment and the visitor experience"; European Journal of Marketing, Vol. $34,3 / 4,2000,261-278$

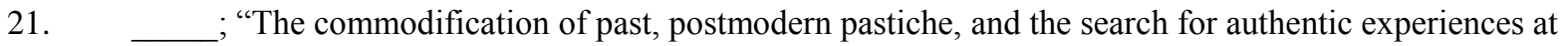
contemporary heritage attractions"; European Journal of Marketing, Vol. 34, 7, 2000, 835-853

22. Hanna, N. and J.S. Wagle; "Who is your satisfied customer?"; Journal of Consumer Marketing, Vol. 6, 1, winter 1989, 53-61

23. Hirschman, E.C. and M.B. Holbrook; "Hedonic consumption: emerging concepts, methods, and propositions"; Journal of Marketing, Vol. 48, summer 1982, 92-101

24. Holbrook, M.B. and M. W. Garyson; "The semiology of cinematic consumption: symbolic consumer behavior in Out of Africa"; Journal of Consumer Research, Vol. 13, Dec 1986, 374-381

25. Hopkinson, G.C., D. Pujari; "A factor analytic study of the sources of meaning in hedonic consumption"; European Journal of Marketing, Vol. 33, 1999, No.3/4, 273-290

26. Hughes, H.; "Arts entertainment and tourism"; 2000

27. Joy, A. and J.F. Sherry; "Speaking of art as embodied imagination: a multisensory approach to understanding aesthetic experience"; Journal of Consumer Research, Vol. 30, 2, Sep 2003, 259-282

28. Keen, G.; "Money and art: a study based on the Times-Sotheby Index”; New York, G.P. Putnam's sons

29. MacLachlan, James; Making a Message Memorable and Persuasive," Journal of Advertising Research, 1983, 23, 6, 51-60

30. McClelland, D.C.; "The achievement motive”; Appleton-Century-Crofts, Inc., New York, 1953

31. _ _ _ "Studies in motivation"; Appleton-Century-Crofts, Inc., New York, 1955

32. _ _ " _ "The achieving society"; The Free Press, New York, 1961

33. _ " "Human motivation"; Cambridge University Press, New York, 1987

34. $\quad \overline{M o w e n}$, J.C. and M.S. Minor; "Consumer behavior: a framework", 1 st edition, 2000; Prentice Hall Inc., Upper Saddle River, New Jersey 
35. Nielsen, R.P. and C. McQueen; "Performing arts audience segments"; Journal of Academy of Marketing Science, (pre-1986), Fall 1974, 2, 602-609

36. O'Curry, S. and M. Strahilevitz; "Probability and mode of acquisition effects on choices between hedonic and utilitarian options"; Marketing Letters, 12:1, 2001, 37-49

37. O'Shaughnessy, J. and N.J. O'Shaughnessy; "Marketing, the consumer society, and hedonism"; European Journal of Marketing, Vol. 36, 5/6, 2002, 524-547

38. Rengers, M. and O. Velthuis; "Determinants of prices for contemporary art in Dutch Galleries, 19921998"; Journal of Cultural Economics, Feb 2002, 26, 1-28

39. Rush, R.H.; “Art as an investment”; Englewood Cliffs, N.J., Prentice Hall, Inc., 1961

40. Schindler, R.M. and M.B. Holbrook; "Nostalgia for early experience as a determinant of consumer preferences"; Psychology \& Marketing, Vol. 20, 4, Apr 2003, 275-302

41. Singer, J.L.; "Daydreaming: an introduction to the experiential study of inner experience"; New York, 1966, Random House

42. Shoham, A., G.M. Rose, L.R. Kahle; "Marketing of risky sports: from intention to action"; Journal of the Academy of Marketing Science, Vol. 26, 1998, No.4, 307-321

43. Snyder, C.R. and H.L. Fromkin; "Uniqueness: the human pursuit of difference"; Plenum Press, New York 1980

44. Stein, J.P.; "The appreciation of paintings"; PhD Dissertation, University of Chicago, 1973

45. Tepper-Tian, K., W.O. Bearden, and G.L. Hunter; "Consumers' need for uniqueness: scale development and validation"; Journal of Consumer Research, Vol. 28, Jun 2001, 50-66

46. Todd, S. and R. Lawson; "Life style segmentation and museum/gallery visiting behavior"; International Journal of Nonprofit and Volunteer Sector Marketing, Vol. 6, 3, 2001, 269-277

47. Veroff, J.; “Assetive motivations: in Motivation and Society, D.G. Winter and A.J. Stewart, eds., JosseyBass Publications, San Fransisco, 1982

48. Wakefield, K.L. and J.H. Barnes; "Retailing hedonic consumption: a model of sales promotion of a leisure service"; Journal of Retailing, Vol. 72, 4, 1996, 409-427

49. Wallack, M.A., N. Kogan, and D.J. Bem; "Group influence on decision making”; Journal of Abnormal and Social Psychology, Vol. 65, Aug 1962, 75-86

50. Winter, D.G.; "The power motive"; The Free Press, New York, 1973 